\title{
HADFIELD'S PROCEDURE FOR DUCT ECTASIA; THE HISTOPATHOLOGICAL SPECTRUM.
}

\footnotetext{
1. MBBS, FCPS Assistant Professor Department of Surgery Sir Syed College of Medical Sciences Karachi.

2. MBBS. FCPS, FICS Professor

Department of Surgery Sir Syed College of Medical Sciences Karachi.

3. MBBS Medical Officer Ayub Teaching Hospital Abbottabad. 4. MBBS, FCPS

Associate Professor Medicine, Rawal Institute of Health Sciences Islamabad.
}

Correspondence Address:

Dr. Nadia Shams

H. No. 879 , Street No. $79,1-8 / 3$ Islamabad.

nadia_shams@yahoo.com

Article received on: 07/01/2019

Accepted for publication: $15 / 09 / 2019$
Fareya Usmani ${ }^{1}$, Imran Munir ${ }^{2}$, Ghazanfar Saleem Jadoon ${ }^{3}$, Nadia Shams ${ }^{4}$

ABSTRACT... Objectives: Mammary duct ectasia, a benign condition of breast is a diagnostic challenge both for surgeon and histo-pathologist. Duct ectasia is commonly encountered in clinical practice and its histo-pathological spectrum needs to be studied in detail in our patients. Study Design: Descriptive cross sectional study. Setting: Sir Syed College of Medical Sciences Karachi after ethical approval. Period: 24 months from June 2016-June 2018. Material \& Methods: Total 104 female patients (>18 years) were included after informed consent. Patients presenting with lump in breast, breast pain, tenderness or nipple discharge were screened by ultrasound breasts or mammography. Pregnant women, patients having high grade fever, hematological abnormalities, coagulopathy, axillary lymphadenopathy, papilloma of nipple, galactocele, lactating mothers and those with past history of malignancy were excluded. Only those cases were included that had diagnosis of duct ectasia on ultrasound breast. Cone excision (Hadfield's operation) was performed after pre-requisites and histo-pathological findings were documented. Patients were kept admitted under observation for minimum 24 hours and then followed up with histo-pathology report. Results: Amongst 104 cases, mean age was $41+6.35$ (range $=30-50$ ) years. The mean duration of symptoms was $11.6+5.76$ (range $=1-24$ ) months. $72(69 \%)$ women were married and $32(30.8 \%)$ were unmarried. As per histo-pathology report duct ectasia was found in $102(98 \%)$, hyperplasia in $61(58.7 \%)$, metaplasia in $41(39.4 \%)$ and atypical cells in $2(1.9 \%)$ samples. Conclusions: Current study demonstrated final outcome of metaplasia in thirty nine percent cases with initial clinical and sonographic diagnosis of duct ectasia. This suggests the triple technique evaluation (i.e. clinical assessment, ultrasound breast/mammography along with histo-pathological assessment) to identify cases with metaplasia. The high risk cases should be frequently followed with clinical assessment and imaging along with BRCA 1 \& 2 gene for timely detection and intervention of breast malignancy.

Key words: $\quad$ Atypical Cells, Ductectasia, Hadfield's Operation, Metaplasia, Mammography.

Article Citation: Usmani F, Munir I, Jadoon GS, Shams N. Hadfield's procedure for Duct Ectasia; the histopathological spectrum. Professional Med J 2020; 27(1):2934. DOI: 10.29309/TPMJ/2020.27.1.3062

\section{INTRODUCTION}

Mammary duct ectasia is also called as peri ductal mastitis or plasma cell mastitis. It is a benign condition of breast that results because of blocked lactiferous ducts. ${ }^{1}$ It may present in perimenopausal or post-menopausal women. The presenting symptoms include pain or discomfort in breasts, nipple discharge/ retraction/ inversion or lump in breast. Superadded infection may lead to systemic features like fever, myalgia, leukocytosis, etc. Nipple discharge is seen in $20 \%$ of duct ectasia cases. The fluid accumulation in lactiferous ducts leads to fibrosis of the ductal walls. Calcification is frequently seen on imaging that may appear as tubular, circular or linear shadows. $^{2}$

Frequent inflammation leads to obliteration of ducts. The accumulated fluid may escape to the breast tissue leading to further inflammation. Duct ectasia hasn't been found to be associated with fibrocystic disease of breast; however its association with breast abscess has been proved in few cases. The resulting localized abscess may mimic malignancy. Differential diagnosis of duct ectasia includes fibrocystic disease of breast, mastitis, breast abscess, fibro-adenoma breast and carcinoma breast. $^{3}$ Hence stepwise diagnostic approach is required to confirm diagnosis and exclude the malignancy. 
There is limited data available about duct ectasia cases in Pakistan. With the increased awareness among women, multiple women seek medical advice from healthcare workers, female physicians and surgeons regarding symptoms related to breast. Current study was conducted for this frequently seen but insufficiently studied disease. Data from this study will be helpful to stratify and study the histo-pathological diagnosis of the clinically diagnosed duct ectasia cases. This will be helpful for health care providers at basic and specialist level to understand and implement the stepwise diagnostic approach for better diagnosis and management of our female patients.

\section{MATERIALS AND METHODS}

This descriptive cross sectional study was conducted at Sir Syed College of Medical Sciences Karachi after ethical approval from review board of institution. The duration of study was 24 months (June 2016-June 2018). The female patients presenting to surgery out door breast clinic were included after informed consent. Total 104 female patients (>18 years) were included by convenience sampling.

Informed consent was obtained from patients presenting with breast pain, tenderness, nipple discharge or lump. These cases were further evaluated by detailed history and clinical examination of breast, axilla and relevant systemic examination. Patients were advised ultrasound breasts (age $<35$ years) or mammography (age $>35$ years). Pregnant women, lactating mothers, patients having high grade fever, suggestive breast abscess cases, axillary or cervical lymphadenopathy, past history of carcinoma breast, papilloma of nipple and galactocoele were excluded. Only those cases were included that had diagnosis of duct ectasia on ultrasound breast/mammography.

Patients were advised complete blood count, coagulation profile, chest X-ray, hepatitis $B$ and $C$ screening. The patients with hematological abnormalities i.e. severe anemia, thrombocytopenia, leukocytosis, coagulopathy or any other contraindication for surgical procedure were excluded.

The selected cases finally underwent cone excision (Hadfield's operation) under general anesthesia after fulfilling pre-requisites for surgery and the collected sample was sent for histopathological assessment.

Patients were kept admitted under observation for minimum 24 hours with administration of medications and then discharged with follow up after one week along with histo-pathology report.

Data was analyzed by SPSS-version 21. Mean and standard deviation calculated for Quantitative variables (i.e. age and duration of symptoms), frequency and percentages calculated for qualitative variables (histo-pathological diagnosis of breast biopsies).

\section{RESULTS}

Total 104 female patients were included. The mean age was $41+6.35$ years (range $=30-50$ years). The mean duration of symptoms was $11.6+5.76$ months (range=1-24 months).

As per marital status, 72(69.2\%) women were married and $32(30.8 \%)$ were unmarried. The ultrasound finding of duct ectasia was found in $104(100 \%)$ cases as per selection criteria of the study. According to the histo-pathology report of biopsy sample, duct ectasia was found in $102(98 \%)$ cases, hyperplasia in $61(58.7 \%)$ and metaplasia in $41(39.4 \%)$ cases. Atypical cells were found in $2(1.9 \%)$ cases.

The average stay at hospital was 24 hours except in one case that was retained for 2 days due to postoperative pain at site. $62(59.6 \%)$ cases complained of mild pain after surgery that was managed by analgesics. $3(2.8 \%)$ patients had mild discharge from surgical wound after the procedure that was managed with short course of oral antibiotics. There was no major complication of procedure in any patient and all the patients were managed and discharged from hospital with scheduled follow up. 


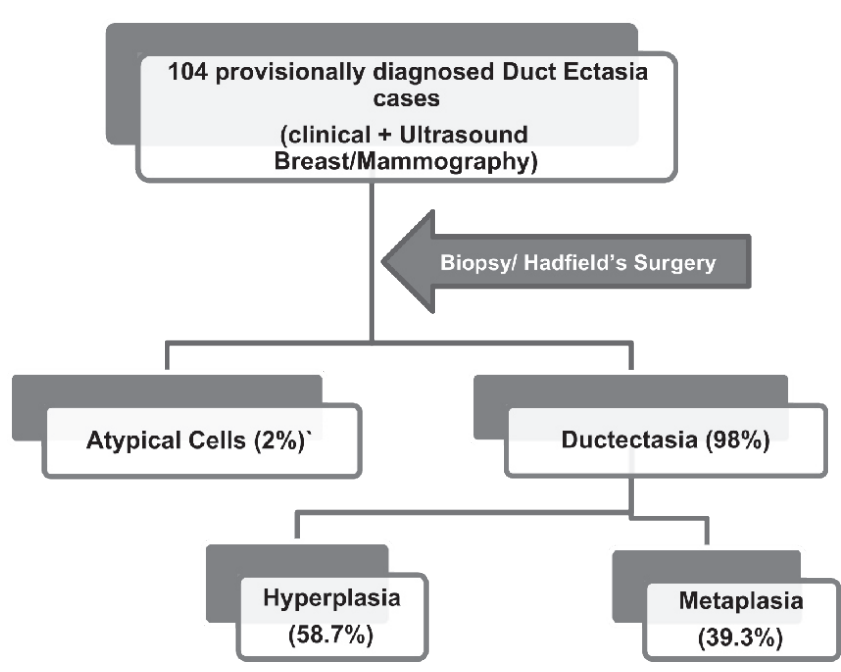

\section{DISCUSSION}

Duct ectasia is a benign breast condition characterized by widening and thickening of mammary ducts. It is a non-cancerous condition also called as mammary duct ectasia or periductal mastitis. It is frequently observed in perimenopausal and post-menopausal women.,5 Duct ectasia usually affects major ducts with unilateral or bilateral involvement.

It predominantly affects females; however few cases of duct ectasia in males also have been reported. Mansel et al ${ }^{6}$ reported three cases of duct ectasia in male as earlier as1978 that presented with bilateral nipple discharge, nipple retraction and peri-areolar inflammation. Conservative management didn't provide satisfactory results in those cases and operative approach was implemented successfully. We included only female cases in our study.

Current study has been conducted on 104 female cases with clinical and sonological diagnosis of duct ectasia. The mean age in study was forty one years, this is in agreement with the reported higher prevalence of duct ectasia in perimenopausal women. ${ }^{7}$ Literature shows mean age of duct ectasia cases to be 45 to 55 years, however certain post-menopausal cases have also been reported. ${ }^{8}$ Khan et $\mathrm{al}^{9}$ conducted study on factors responsible for delay in presentation of women with breast lump from Northern Pakistan. The common reasons were painless lump, shyness, lack of access to female doctor, ongoing pregnancy or lactation, illiteracy, low socioeconomic status and alternative /traditional medicine use.

The mean duration of symptoms in our cases was approx. one year with fewer cases presenting during initial 6 months. This indicates the delay in approaching healthcare facility. The contributing factors could be lack of access to healthcare facility, social norms and beliefs, financial constraints, dependency of females on other family members for healthcare and non-availability of female surgeons in vicinity. Elzawawy et $\mathrm{al}^{10}$ in an Egyptian study conclude that the delay in presentation of patients with breast complaints is multifactorial with major contributors being financial constraints, insufficient diagnostic and management facilities and lack of screening programs for early detection.

Certain studies have reported a mean lag time (i.e. the time between onset of symptoms and approach to health care facility) to be as long as 18 months, however western studies report shorter lag time as compared to under developed countries. ${ }^{11,12}$ Authors suggest the need to increase awareness in our community for timely approach to healthcare for breast issues. A study conducted by Naqvi et $\mathrm{al}^{13}$ in Karachi reported scarcity of knowledge about breast cancer among participants, 50\% women denied the breast screening and $88 \%$ women preferred a female physician to discuss their breast issues. The literature in local language, availability of female doctors and counselors may help in dealing with communication barrier along with proper physical examination and evaluation of our female patients.

As per marital status $2 / 3^{\text {rd }}$ of cases were married and $1 / 3^{\text {rd }}$ were unmarried. Certain studies have been conducted addressing risk factors for duct ectasia with no proven association of marital status, parity, oral contraceptive use, history of abortions, miscarriages or breast abscess. However, history of active smoking was found to be associated with duct ectasia. ${ }^{14}$ In Asian countries, prevalence of smoking is comparatively low among females and none of our patients gave 
history of cigarette smoking.

The most commonly used procedure for duct ectasia cases is Hadsfield's operation. This technique is diagnostic as well as therapeutic and has been practiced since $1960 .^{15}$ This procedure involves micro-dochectomy along with isolating and removing the affected ducts. We selected 104 cases meeting the clinical and sonological criteria for diagnosis of duct ectasia. These cases were then prepared for cone biopsy for histo-pathological confirmation of diagnosis. The cone excision (Hadfield's operation i.e. radical sub-areolar duct excision) was performed under aseptic technique under general anesthesia and sample was sent for histo-pathological analysis. None of the patients reported any major complications postsurgical. However few cases reported pain at incision site that was managed with painkillers. 3 cases reported mild discharge from surgical wound that was recovered with oral antibiotic course.

Among the 104 cases with clinical diagnosis of duct ectasia, the histo-pathological findings of duct ectasia were confirmed in 102 cases. Hence, we may conclude that breast ultrasound/ mammography is a reliable method to screen for duct ectasia. Amongst 104 cases, two cases were found to have atypical cells on biopsy. Though duct ectasia is a benign condition, however few cases with malignancy may be misinterpreted as duct ectasia.

The finding of metaplasia was found in 39.4\% cases. That is a significant number of cases. As per guidelines, the cases with metaplasia need frequent monitoring and follow up to exclude the malignancy. Metaplasia reveals histopathological findings of columnar cells with eosinophilic granular cytoplasm. These cells are found in the lining of the dilated ducts or papillary proliferations. Though metaplasia is a benign condition, however findings of the apocrine breast metaplasia and apocrine breast carcinoma share some histo-pathological findings that may lead to mis-interpretation of results. Hence it is recommended that patients with metaplasia may be followed with clinical examination and ultrasound breast/ mammogram.

Current study found hyperplasia in $59 \%$ cases that is the diagnostic challenge. It is frequently seen form of proliferative breast disease. It may be difficult to differentiate between the ductal/ lobar hyperplasia and their atypical counterparts as well. ${ }^{16}$

A Saudian study conducted by Abdulkader et al ${ }^{17}$ conducted upon 603 cases concluded that $60 \%$ of the breast biopsies had benign lesions. Approx. half of these were fibro-adenoma breast, $1 / 4^{\text {th }}$ showed fibrocystic change and less than $15 \%$ had inflammatory lesions that included granulomatous mastitis, chronic mastitis, breast abscess, fibroadenomatoid hyperplasia, intraductal papilloma and benign phylloides tumor.

Certain limitations of the study to be mentioned are the sampling technique and the extensive investigation by genetic screening. The underlying reason could be non-availability of genetic screens (BRCA-1 \& 2) in many centers. The unbearable cost of these tests imposes financial constraints. Wiliam et $\mathrm{al}^{18}$ reported the cost of BRCA-1 \& 2 along with counseling as much as $2000 \$$.

Siddiqui et $\mathrm{al}^{19}$ studied the 3279 histo-pathological breast biopsy samples received at Agha Khan University Hospital Karachi, and among these $5.3 \%$ had duct ectasia. Aslam et $\mathrm{al}^{20}$ found benign lesions in $75 \%$ of breast biopsy samples. There is limited research data available on duct ectasia from Pakistan, though there are multiple articles addressing carcinoma breast. Results of current study may help us obtain regional data and compare with international studies. This may also help us to understand and implement the sequence of diagnostic and therapeutic approach in duct ectasia cases. Early detection of the atypical cells or metaplasia can guide us to filter out the high risk cases with frequent follow up and management.

\section{CONCLUSIONS}

Current study demonstrated final outcome of metaplasia in thirty nine percent cases with initial 
clinical and sonographic diagnosis of duct ectasia. This suggests the triple technique evaluation (i.e. clinical assessment, ultrasound breast/ mammography along with histopathological assessment) to identify cases with metaplasia. The high risk cases should subsequently be followed with clinical assessment and imaging along with BRCA 1 \& 2 gene for timely detection and intervention of breast malignancy.

Copyright@ 15 Sep, 2019.

\section{REFERENCES}

1. Rosai J. Breast. In: Rosai and Ackerman's surgical pathology. Philadelphia, Pa.: Mosby Elsevier; 2011. https://www.clinicalkey.com. Accessed Nov. 5, 2018.

2. Kim KW, Cho KR, Seo BK et al. Sonographic findings of mammary duct ectasia: Can malignancy be differentiated from benign disease? J Breast Cancer 2010; 13(1):19-26.

3. Noncancerous breast conditions. American Cancer Society. http://www.cancer.org/healthy/ findcancerearly/ womenshealth/non-cancerousbreastconditions/noncancerous-breast-conditions-duct-ectasia. Accessed Nov. 5, 2018.

4. Duct ectasia of breast. Pathology outlines.com website. http://www.pathologyoutlines.com/ topic/ breast duct ectasia.html. Accessed Nov 30th, 2018.

5. S. Hari, J. Kumar, A. Kumar \& S. Chumber. Bilateral severe mammary duct ectasia. Acta Radiologica. 2007:48(4); 398-400.

6. Mansel RE, Morgan WP. Duct ectasia in the male. $\mathrm{Br} \mathrm{J}$ Surg. 1979 Sep; 66(9):660-2.

7. Rahal RM, de Freitas-Júnior R, Paulinelli RR. Risk factors for duct ectasia. Breast J. 2005; 11(4): 262-5.

8. Onstad $\mathrm{M}$, et al. Benign breast disorders. Obstetrics and Gynecology Clinics of North America. 2013; 3:459.

9. Khan MA, Hanif S, Iqbal S, Shahzad MF, Shafique $S$, Khan MT. Presentation delay in breast cancer patients and its association with sociodemographic factors in North Pakistan. Chin J Cancer Res. 2015; 27(3):288-93.

10. Elzawawy AM, Elbahaie AM, Dawood SM, Elbahaie HM, Badran A. Delay in seeking medical advice and late presentation of female breast cancer patients in most of the world. Could we make changes? The Experience of 23 Years in Port Said, Egypt. Breast Care. 2008; 3(1):37-41. doi:10.1159/000113936.
11. Dye TD, Bogale S, Hobden C, Tilahun Y, Deressa T, Reeler A. "Experience of initial symptoms of breast cancer and triggers for action in ethiopia," Int J Breast Cancer. 2012, Article ID 908547, 5 pages, 2012. https:// doi.org/10.1155/2012/908547.

12. Akuoko CP, Armah E, Sarpong T, Quansah DY, Amankwaa I, Boateng D (2017) Barriers to early presentation and diagnosis of breast cancer among African women living in sub-Saharan Africa. PLOS ONE 12(2): e0171024.

13. Naqvi AA, Zehra F, Ahmad R, Ahmad N, Yazdani N, et al. Awareness, knowledge and attitude towards breast cancer, breast screening and early detection techniques among women in Pakistan. J Pak Med Assoc. 2018; 68(4):576-584.

14. Rahal RM, de Freitas-Júnior R, Paulinelli RR. Risk factors for duct ectasia. Breast J. 2005; 11(4): 262-5.

15. Hadfield J. Excision of the major duct system for benign disease of the breast. Br J Surg. 1960; 47:47277.

16. Guray $M$, Sahin AA. Benign breast diseases: Classification, diagnosis, and management. Oncologist 2006; 11:435-49.

17. Albasri AM. Profile of benign breast diseases in western Saudi Arabia. An 8-year histopathological review of 603 cases. Saudi Med J. 2014; 35(12):151720.

18. Lawrence WF, Peshkin BN, Liang W, Lerman C, Mandelblatt JS. Cost of genetic counseling and testing for brca1 and brca2 breast cancer susceptibility mutations. Cancer Epidemiol Biomarkers Prev. 2001; 10(5):475-48.

19. Siddiqui M, Kayani N, Gill M, Pervez S, Muzaffar S, Aziz S, Setna Z, Israr M, Hasan S. Breast diseases: A histopathological analysis of 3279 cases at a tertiary care center in Pakistan. J Pak Med Assoc. 2003; $53(3): 94-97$.

20. Aslam HM, Saleem S, Shaikh HA, Shahid N, Mughal A, Umah R. Clinico- pathological profile of patients with breast diseases. Diagn Pathol. 2013; 8:77. Published 2013 May 9. doi:10.1186/1746-1596-8-77. 


\section{AUTHORSHIP AND CONTRIBUTION DECLARATION}

\begin{tabular}{|c|c|c|c|}
\hline Sr. \# & Author(s) Full Name & Contribution to the paper & Author(s) Signature \\
\hline 1 & Fareya Usmani & $\begin{array}{l}\text { Data collection, Write up, } \\
\text { referencing. }\end{array}$ & \\
\hline 2 & Imran Munir & $\begin{array}{l}\text { Data collection, Write up, } \\
\text { Literature review. }\end{array}$ & \\
\hline 3 & Ghazanfar Saleem Jadoon & $\begin{array}{l}\text { Data collection, Write up, } \\
\text { Literature review. }\end{array}$ & $\operatorname{anf}$ ar \\
\hline 4 & Nadia Shams & $\begin{array}{l}\text { Data collection, data } \\
\text { analysis, write up, literature } \\
\text { review, referencing. }\end{array}$ & \\
\hline
\end{tabular}

